DUARTE, R.L.R.; VELOSO, M.E.C.; MELO, F.B.; ATHAYDE SOBRINHO, C.; RIBEIRO, V.Q.; SILVA, P. H.S. Produtividade de cultivares de cebola no Semi-árido piauiense. Horticultura Brasileira, Brasília, v. 21, n. 1, p. 34-36, março 2003.

\title{
Produtividade de cultivares de cebola no Semi-Árido piauiense
}

\author{
Rosa Lúcia R. Duarte; Marcos Emanuel da C. Veloso; Francisco de B. Melo; Cândido Athayde Sobrinho; \\ Valdenir Q. Ribeiro; Paulo Henrique S. da Silva
}

Embrapa Meio-Norte, C. Postal 01,64.006-220 Teresina-PI. E-mail: rlucia@cpamn.embrapa.br

\begin{abstract}
RESUMO
Objetivando selecionar e indicar cultivares de cebola mais produtivas para a região semi-árida, conduziu-se um experimento no período de maio a outubro de 1999, sob regime de irrigação por microaspersão no município de Sussuapara, PI. O delineamento estatístico utilizado foi de blocos ao acaso com 18 tratamentos e quatro repetições. As cultivares avaliadas foram: Granex 33, Composto IPA-6, Belém IPA-9, Franciscana IPA-10, Vale Ouro IPA-11, Texas Grano 502, Conquista, Crioula, Serrana, Granex 429, Régia, Princesa, Mercedes, Duquesa, Linda Vista, Piraouro, Granex Ouro e Baia Periforme Precoce. As características avaliadas foram produtividade de bulbos comerciais e não comerciais. Dividiu-se as cultivares em três grupos considerando a produtividade de bulbos, pelo teste de Scott-Knott $(\mathrm{P}<0,05)$. O primeiro grupo apresentou produtividade entre 43,7 t/ha e 40,5 t/ha, com média de 41,9 t/ha. No segundo, a produtividade variou de $39,9 \mathrm{t} / \mathrm{ha}$ a $34,6 \mathrm{t} / \mathrm{ha}$ e no terceiro de 32,4 $\mathrm{t} / \mathrm{ha}$ a $26,9 \mathrm{t} / \mathrm{h}$. As cultivares mais produtivas foram Vale Ouro IPA11, Franciscana IPA-10 e Mercedes, com respectivamente, 43,7 t/ ha, 41,5 t/ha e 40,5 t/ha de bulbos comerciais, respectivamente.
\end{abstract}

Palavras-chave: Allium cepa, rendimento de bulbos, adaptação.

\begin{abstract}
Yield of onion cultivars in the semi-arid region of Piauí State, Brazil

The yield of onion cultivars was evaluated in the Picos region, Brazil, from May to October 1999. The experimental design was of randomized complete blocks with 18 treatments and four replications. The cultivars Granex 33, Composto IPA-6, Belém IPA9, Franciscana IPA-10, Vale Ouro IPA-11, Texas Grano 502, Conquista, Crioula, Serrana, Granex 429, Régia, Princesa, Mercedes, Duquesa, Linda Vista, Piraouro, Granex Ouro and Baia Periforme Precoce were evaluated. We evaluated the commercial and noncommercial bulb yield. The cultivars were grouped in three classes according to bulb yield (>40 t/ha; 39.9-34.6 t/ha; 32.4-26.9 $\mathrm{t} / \mathrm{ha}$ ). The average onion bulbs yield was $41,9 \mathrm{t} / \mathrm{ha}$. The most productive cultivars (commercial bulbs) were Vale Ouro IPA-11 (43,7 t/ha), Franciscana IPA-10 (41,5 t/ha) and Mercedes (40,5 t/ha).
\end{abstract}

Keywords: Allium cepa, yield, adaptation.

\section{(Recebido para publicação em 15 de agosto de 2001 e aceito em 10 de outubro de 2002)}

A cebola (Allium cepa L.) destacae dentre as várias espécies agrícolas cultivadas, pelo volume de consumo e valor econômico (Melo \& Ribeiro, 1990). No Brasil ocupa o $4^{0}$ lugar, dentre as hortaliças, em importancia econômica (Mascarenhas \& Rocha,1991) com uma produtividade média de 12,5 t/ha (ANUÁRIO,1996).

A produção brasileira, até 1986 era de 700 mil toneladas anuais e o abastecimento do mercado interno de cebola foi realizado com produto brasileiro e não necessitou de importação. Os preços altos da entressafra de 1990 (março a julho) proporcionaram a entrada de cebola argentina no mercado brasileiro que foi consolidado com o início do Mercosul. Estes dois países respondem pela maior oferta de cebola do referido mercado, sendo as produções do Uruguai e Paraguai incipientes com cerca de 3,5\%.

A cebola brasileira apresentou variação positiva de $7,3 \%$ na estimativa de produção em maio de 2000 de $995.393 \mathrm{t}$, em relação ao ano de 1999 que foi
927.700,00 t (Camargo Filho, 1995). Os maiores produtores são os estados de Santa Catarina, Rio Grande do Sul, São Paulo, Minas Gerais, Pernambuco e Bahia, contribuindo com $37,7 \%$ (região sul), 35,3\% (Sudeste) e 27\% (Nordeste) da produção nacional, respectivamente. No Nordeste, os maiores produtores (Pernambuco e Bahia) apresentaram produtividade média de 14,9 t/ha e 14,7 t/ ha, respectivamente (ANUÁRIO, 1996).

As pesquisas têm mostrado que as melhores cultivares são aqueles obtidas na própria região de produção, porque cada uma requer condições especiais de fotoperíodo e temperatura para a obtenção das características desejáveis, alta produtividade e boa conservação no armazenamento (Jones \& Man, 1963).

Estudando a adaptação de cultivares de cebola nas condições do Vale do Submédio São Francisco, região semiárida, Costa et al. (2000) observaram que a produtividade de bulbos comerciais variou de 21,4 a 61,8 t/ha destacandose as cultivares Granex 429 (58,3 t/ha),
Texas Grano 502 (53,9 t/ha), Franciscana IPA-10 (42,7 t/ha) e Vale Ouro IPA-11 (39,5 t/ha). As cultivares Composto IPA-6, Belém IPA-9, Conquista e Crioula, apresentaram os menores rendimentos de $34,7 \mathrm{t} / \mathrm{ha}, 33,8 \mathrm{t} /$ ha, 29,4 t/ha e 22,3 t/ha. Caraballo et al. (1990), verificaram produtividade de 33,1 e 32,2 t/ha para as cultivares Granex-33 e Granex 429, respectivamente. Murakami et al. (1995), avaliando o comportamento de cultivares de cebola, verificaram que a cultivar Régia foi a mais produtiva (90,3 t/ha). Segundo Gandim et al. (1989), avaliando cultivares de cebola de ciclo precoce, observaram produtividade que variou de 32,3 a $17,5 \mathrm{t} /$ ha destacando-se as cultivares IPA-1 (29,4 t/ha), IPA-2 (28,3 t/ ha) e Composto IPA-6 (27,7 t/ha).

No Piauí, a cebola é cultivada na microrregião de Picos por pequenos agricultores com produtividade em torno de 4,1 t/ha (ANUÁRIO, 1996). A contribuição da produção piauiense de cebola comercializada na Ceasa-PI é inferior a 1\% (Ceasa-PI, 2001). 
Tabela 1. Produtividade de bulbos comerciais (PBC), percentagem de bulbos não comerciais (PBNC) e ciclo da planta, de dezoito cultivares de cebola. Sussuapara, Embrapa Meio-Norte, 1999.

\begin{tabular}{lccc}
\hline \multicolumn{1}{c}{ Tratamento } & PBC (t/ha) & PBNC (\%) & Ciclo (dias) \\
\hline Vale Ouro IPA-11 & $43,7 \mathrm{a}$ & 0,12 & 117 \\
Franciscana IPA-10 & $41,5 \mathrm{a}$ & 0,07 & 150 \\
Mercedes & $40,5 \mathrm{a}$ & 0,05 & 150 \\
Princesa & $38,9 \mathrm{~b}$ & 0,10 & 150 \\
Granex 33 & $38,1 \mathrm{~b}$ & 0,07 & 150 \\
Duquesa & $38,0 \mathrm{~b}$ & 0,06 & 117 \\
Régia & $37,8 \mathrm{~b}$ & 0,14 & 133 \\
Granex 429 & $37,3 \mathrm{~b}$ & 0,19 & 148 \\
Serrana & $36,8 \mathrm{~b}$ & 0,11 & 117 \\
Composto IPA - 6 & $36,8 \mathrm{~b}$ & 0,12 & 117 \\
Texas Grano 502 & $35,4 \mathrm{~b}$ & 0,14 & 133 \\
Baia Periforme Precoce & $34,6 \mathrm{~b}$ & 0,16 & 133 \\
Piraouro & $32,4 \mathrm{c}$ & 0,24 & 117 \\
Linda Vista & $32,3 \mathrm{c}$ & 0,17 & 117 \\
Granex Ouro & $30,1 \mathrm{c}$ & 0,17 & 150 \\
Conquista & $29,2 \mathrm{c}$ & 0,23 & 117 \\
Crioula & $28,1 \mathrm{c}$ & 0,14 & 117 \\
Belem IPA - 9 & $26,9 \mathrm{c}$ & 0,20 & \\
\hline C.V (\%) & 8,26 & & \\
\hline
\end{tabular}

*/ Médias seguidas de uma mesma letra minúscula na vertical não diferem entre si, pelo teste Scott-Knott ao nível de 5\% de probabilidade (P<0,05).

Neste sentido, objetivou-se avaliar e identificar cultivares de cebola adaptadas às condições do semi-árido piauiense, de alto potencial produtivo para produção de bulbos.

\section{MATERIAL E MÉTODOS}

$\mathrm{O}$ experimento foi instalado no município de Sussuapara, PI, região semiárida, onde o clima segundo a classificação de Koeppen, é do tipo Bsh, quente e semi-árido com estação chuvosa no verão (IPAM, 1978).

Utilizou-se o delineamento experimental de blocos ao acaso com 18 tratamentos, constituídos por cultivares (Vale Ouro IPA-11, Franciscana IPA-10, Mercedes, Princesa, Granex 33, Duquesa, Régia, Granex 429, Serrana, Composto IPA-6, Texas Grano 502, Baia Periforme Precoce, Piraouro, Linda Vista, Granex Ouro, Aurora, Crioula e Belem IPA-9), com quatro repetições. A semeadura em sementeira foi realizada em 19/05/1999 em sulcos espaçados de $10 \mathrm{~cm}$, profundidade de $2 \mathrm{~cm}$ e densidade de semeadura de 8 a $10 \mathrm{~g}$ de se- mentes $/ \mathrm{m}^{2}$ de sementeira. Posteriormente, a sementeira foi coberta com palha de carnaúba que foi retirada tão logo as plântulas começaram a emergir. O transplantio para o local definitivo foi realizado em 23/06/1999. Cada parcela foi representada por uma área de 3,0 $\mathrm{x}$ $1,0 \mathrm{~m}$ com 150 plantas, área útil de 2,16 $\mathrm{m}^{2}$ com 144 plantas, no espaçamento de $15 \times 10 \mathrm{~cm}$. A adubação química foi efetuada de acordo com os resultados da análise do solo, constituindo-se de 120 $\mathrm{kg} / \mathrm{ha}$ de $\mathrm{P}_{2} \mathrm{O}_{5}, 20 \mathrm{~kg} / \mathrm{ha} \mathrm{de} \mathrm{N} \mathrm{(1/3} \mathrm{do}$ total) e $30 \mathrm{~kg} / \mathrm{ha} \mathrm{de} \mathrm{K}_{2} 0$ (1/2 do total). Os adubos foram incorporados a uma profundidade aproximada de $25 \mathrm{~cm}$. O nitrogênio e o potássio restantes foram aplicados em cobertura, em duas parcelas iguais, ou seja, $30 \mathrm{~kg} / \mathrm{ha}$ de $\mathrm{N}$ e 15 $\mathrm{kg} / \mathrm{ha}$ de $\mathrm{K}_{2} 0$ aos 25 e 35 dias após o transplantio. Utilizou-se o sulfato de amônio, o superfosfato triplo e o cloreto de potássio como fontes de nitrogênio, fósforo e potássio, respectivamente.

Irrigou-se o experimento por microaspersão. $\mathrm{O}$ manejo da irrigação foi baseado na evaporação do Tanque classe A, fornecido pela Estação
Meteorológica de Picos e monitorada por tensiômetros instalados nas linhas de plantio da cebola a 15 e $30 \mathrm{~cm}$ de profundidade. As capinas foram feitas manualmente, de acordo com as necessidades requeridas.

A colheita das cultivares foi efetuada quando a maioria das plantas encontrava-se tombada, com início aos 117 dias, prolongando-se até 150 dias após a colheita, em algumas cultivares. Avaliou-se a produtividade comercial (diâmetro $>35 \mathrm{~mm}$ ) e não comercial de bulbos (diâmetro<35 mm).

\section{RESULTADOS E DISCUSSÃO}

As cultivares foram divididas em três grupos, considerando o rendimento de bulbos, pelo teste de Scott-Knott $(\mathrm{P}<0,05)$ (Tabela 1). Observou-se diferenças significativas quanto à produtividade de cebola nas condições climáticas do semi-árido piauiense, verificando-se que as cultivares do primeiro grupo, (Vale Ouro IPA-11, Franciscana IPA-10 e Mercedes) apresentaram produtividade de bulbos comerciais de 43,7 
t/ha a 40,5 t/ha, não diferindo significativamente entre si. Estes resultados corroboraram com os obtidos por Costa $e t$ al. (2000) para as cultivares Franciscana IPA-10 e Vale Ouro IPA-11, que apresentaram rendimentos de $42,7 \mathrm{t} / \mathrm{ha} \mathrm{e}$ $39,5 \mathrm{t} / \mathrm{ha}$, respectivamente. No segundo grupo, as cultivares Princesa, Granex 33, Duquesa, Régia, Granex 429, Serrana, Composto IPA-6, Texas Grano 502 e Baia Periforme Precoce não diferiram estatisticamente entre si, apresentando produtividade variando de 38,9 a 34,6 t/ha. Entretanto, Costa et al. (2000) obtiveram alto desempenho com as cultivares Granex 429 (58,3 t/ha) e Texas Grano 502 (54,0 t/ha) mostrando a grande adaptação destas, às condições do semi-árido do Vale do São Francisco. No terceiro grupo as cultivares Piraouro, Linda Vista, Granex Ouro, Conquista, Crioula e Belém IPA-9, não diferiram entre si $(\mathrm{P}<0,05)$, com produtividade variando de $32,4 \mathrm{t} / \mathrm{ha}$ a $26,9 \mathrm{t} / \mathrm{ha}$, sendo os mais baixos rendimentos obtidos, apresentando porém, diferenças significativas quando comparadas com as cultivares do primeiroe segundo grupo. Resultados semelhantes foram obtidos por Costa et al. (2000) para as cultivares Belém IPA-9, Conquista e Crioula que apresentaram produtividade de 33,8 ; 29,4 e 22,3 t/ha, revelando a baixa adaptação destas cultivares às condições climáticas do semi-árido do Vale do São Francisco. Dados obtidos por Resende et al. (1996), em Porteirinha (MG), mostraram o baixo desempenho das cultivares Baia Periforme Precoce e Composto IPA-6 em condições de cultivo de verão, com produtividade de 8,2 e 12,1 t/ha, respectivamente.

A produtividade média das cultivares de melhor comportamento produtivo foi de 41,9 t/ha destacando-se as cultivares Vale Ouro IPA-11, Franciscana IPA-10 e Mercedes com rendimentos de 43,7 t/ha, 41,5 t/ha e 40,5 t/ha. Estas cultivares apresentaram incrementos na produtividade da ordem de $334,9 \%$ acima da média nacional (12,5 t/ha); sendo superiores, no Nordeste Brasileiro, às produtividades médias obtidas nos estados de Pernambuco (14,0 t/ha), Bahia (13,6 t/ha) e Sergipe (4,3 t/ha) (ANUÁRIO, 1996). Verificou-se baixa percentagem de bulbos não comerciais, nas cultivares Mercedes (5\%), Granex $33(5 \%)$, Duquesa $(6 \%)$ e Franciscana IPA-10 (7\%). A maior percentagem de bulbos não comerciais foi obtida pela cultivar Piraouro (24\%), seguida da 'Aurora' (23\%) e 'Belém IPA-9' (20\%) (Tabela 1).

Considerando o aspecto produtividade comercial, concluiu-se que neste trabalho os melhores resultados foram obtidos pelas cultivares Vale Ouro IPA11 (43,7 t/ha) Franciscana IPA-10 (41,5 t/ha) e Mercedes (40,5 t/ha), mostrando a grande adaptação e viabilidade de cultivo destes materiais nas condições do semi-árido piauiense.

\section{LITERATURA CITADA}

ANUÁRIO ESTATÍSTICO DO BRASIL. Rio de janeiro: IBGE, v. 56, 1996.

CAMARGO FILHO, W.P. Cebolicultura brasileira e mercosul. Informações Econômicas, São Paulo, v. 25, n. 7, p. 13-22, 1995.

CARABALLO, E.; FORNARIS, G.J.; GUADALUPE, R.; HERNADEZ, E.R. Performance sizing and total solids of nine onion (Allium cepa L.) cultivars. Journal of Agriculture of the Puerto Rico, Puerto Rico, v. 74, n. 1, p. 2127, 1990.

COSTA, N.D; RESENDE, G.M.; SOUZA DIAS, R.C. Avaliação de cultivares de cebola em Petrolina-PE. Horticultura Brasileira, Brasília, v. 18, n. 1, p. 57-60, 2000.

GANDIN, C.L.; TORRES, L.; GUIMARÃES, D.R.; THOMAZELLI, L.F.; DITRICH, R.C. Competição de cultivares de cebola. Agropecuária Catarinense, Santa Catarina, v. 2, n. 2, p. 52-54, 1989.

IPAM. Um município piauiense - Picos. Teresina, 1978. 155 p.

JONES, H.A.; MAN, L.K. Onion and their allies. New York: Interscience, 1963. 283 p.

MASCARENHAS, M.H.T.; ROCHA, F.E.C. Panorama da mecanização na olericultura brasileira. Informe Agropecuário, Belo Horizonte, v. 15, n. 169 , p. 5 -10, 1991.

MELO, P.C.T.; RIBEIRO, A. Produção de sementes de cebola: cultivares de polinização aberta e híbridos. In: CASTELLANE, P.D.; NICOLOSI, W.M.; HASEGAWA, M. (Coord.) Produção de sementes de hortaliças. Jaboticabal: FCA/FUNEP, 1990. p. 15-59.

MURAKAMI, J.; ARAÚJO, M.T.; CHURATAMASCA, M.G.C. Avaliação de genótipos selecionados de cebola. Horticultura Brasileira, Brasília, v. 13, n. 1, p. 95-97, 1995.

RESENDE, G.M.; GOULART, A.C.P.; SILVA, R.A. Características de produção de cultivares de cebola em cultivo de verão. Horticultura Brasileira, Brasília, v. 14, n. 2, p. 151-157, 1996. 